GAPP. Revista Gestión y Análisis de Políticas Públicas

Nueva Época, no 5, enero-junio 2011, pp. 61-77

ISSN: 1134-6035

\title{
La gestión paritaria en Francia
}

\author{
Eguzki Urteaga \\ Universidad del País Vasco \\ eguzki.urteaga@ehu.es
}

\begin{abstract}
Resumen
La gestión paritaria constituye un mecanismo que reúne a los representantes patronales y sindicales para asegurar conjuntamente una misión de interés general en el ámbito laboral. Conoce un desarrollo notable en las instituciones de protección social que se ponen en marcha en Francia a partir de la posguerra. Es un producto de la práctica contractual y de las decisiones del poder político que ilustra la institucionalización paradójica del sistema de relaciones laborales francés. Se trata de un procedimiento que pretende estructurar, a través de la combinación de intereses distintos y organizados, la relación capital/trabajo para asociar la representación y la producción de bienes colectivos o de reglas establecidas en la consecución del interés general. Los agentes sociales tienen dificultades para concluir pactos sociales, aunque gestionen numerosas instituciones del Estado de bienestar. Por la presencia histórica del Estado en la gestión de la Seguridad Social y su intervención creciente en eI UNEDIC, ciertos observadores consideran que se trata cada vez más de una gestión paritaria ilusoria.
\end{abstract}

Palabras clave

Gestión paritaria, agentes sociales, protección social, Francia.

\section{The Joint Management in France}

\begin{abstract}
The joint management constitutes a device that associates the employer and trade union representatives to assure jointly a mission of general interest in the labour world. He knows an important development in the institutions of social protection that are started from the postwar period. The joint management is a product of the contractual practice and of the decisions of the political power that illustrates the paradoxical institutionalization of the French system of labour relations. It is a question of a procedure that tries to structure, across the combination of different and organized interests, the relation between capital and work to associate the representation and the production of collective goods or to establish rules in the attainment of the general interest. Because of the historical presence of the State in the management of the social Safety and his increasing intervention in the UNEDIC, certain observers consider that it is increasingly an illusory joint management.
\end{abstract}

Key words

Joint management, social agents, social protection, France. 


\section{INTRODUCCIÓN}

La gestión paritaria constituye fundamentalmente un mecanismo que reúne a los representantes patronales y sindicales para asegurar conjuntamente una misión de interés general en el ámbito laboral. Nace de las relaciones laborales (Consejos de prud'hommes, en 1848; Cajas de Jubilaciones Obreras y Campesinas, en 1910; Consejo Nacional Económico, en 1924), conoce un notable desarrollo en las instituciones de protección social que se ponen en marcha a partir de la Liberación (1945). Hasta entonces, los modelos de organización eran diversos, puesto que "la gestión patronal, la gestión obrera y el mutualismo conviven con una gestión tripartita, generalmente vinculada a la participación financiera y/o a la intervención de salvaguardia del Estado" (Duclos, 2006: 58). El Ilamamiento a los agentes sociales para gestionar en nombre de los interesados la Seguridad Social, creada en 1945, es pensada, sin embargo, en unos términos de democracia social. Según Friot (1997), esta noción hace referencia a unas instituciones financiadas por las cotizaciones sociales, consideradas como una parte del salario, y gestionadas mayoritariamente por los actores implicados, en las cuales la tutela estatal no sustituye al poder de gestión de las Cajas.

La gestión paritaria se impone con los regímenes complementarios de jubilación y sobre todo con la UNEDIC'. Dicho solo aparece de manera tardía y será popularizado al inicio de los años 1960 por André Bergeron, una de las grandes figuras del modelo paritario. Solicitado por Pompidou en 1967 para trabajar tanto en la Seguridad Social como en la UNEDIC, rechaza la propuesta porque el problema era diferente en aquel contexto socio-político. La UNEDIC, que es presidida en alternancia entre los representantes de las centrales sindicales y de la patronal entre 1959 y 1990, ilustra "su fundamento filosófico y político" (Bergeron, 2004). Más allá de las diferencias que ponen de manifiesto las dos nociones de democracia social y de gestión paritaria, ambas hacen referencia a una esfera social reservada a los agentes sociales por los poderes públicos para conseguir una regulación compartida.

La gestión paritaria es, por lo tanto, un producto de la práctica contractual y de una decisión del poder político. Constituye una perfecta ilustración de la institucionalización paradójica del sistema de relaciones laborales francés. Este "procedimiento pretende estructurar, a través de la combinación de distintos intereses organizados, la relación capital/trabajo para asociar la representación y la producción de bienes colectivos o de reglas establecidas para la consecución del interés general" (Duclos, 2006: 19). Por la presencia histórica del Estado en la gestión de la Seguridad Social y su intervención creciente en la UNEDIC, ciertos observadores consideran que se trata cada vez más de una gestión paritaria ilusoria.

1 La Unión Nacional Interprofesional para el Empleo en la Industria (UNEDIC) y el Comercio es una asociación dirigida por los agentes sociales que se encarga de la gestión del seguro de desempleo, teniendo en cuenta que dicho seguro está financiado por las cotizaciones de los trabajadores y de las empresas del sector privado. Asegura una renta de sustitución a los trabajadores involuntariamente privados de empleo

62 y favorece un retorno al empleo a través de la financiación de ayudas y de prestaciones adecuadas. 


\section{LAS PRINCIPALES INSTITUCIONES DE LA GESTIÓN PARITARIA}

Se distinguen habitualmente dos tipos de gestiones paritarias: el amplio y el estrecho. El primero asocia los agentes sociales, y a veces a otros actores concernidos, a la gestión de los servicios sociales que aspiran a encarnar el interés general. Los agentes sociales no están necesariamente representados de manera igualitaria y el papel del Estado sigue siendo notable. La Seguridad Social pertenece a este tipo. El segundo se caracteriza por un número similar de administradores que representan a los trabajadores y a los empleadores, a los que se confiere una delegación para administrar un servicio de interés general. Las Cajas de Jubilaciones Complementarias, como la $A_{G I R C^{2}}$ y el seguro de desempleo (UNEDIC), obedecen, por lo menos en sus orígenes, a esta concepción de la gestión paritaria. Las instituciones de formación profesional y los prud'hommes pueden igualmente ser consideradas como pertenecientes a este tipo de gestión paritaria, sin olvidar que la función pública ofrece asimismo numerosos ejemplos de instituciones paritarias.

\subsection{La Seguridad Social}

Una disposición del 4 de octubre de 1945 instaura "una organización de la Seguridad Social destinada a proteger a los trabajadores y a sus familias frente a los riesgos de cualquier naturaleza". Esta decisión se inscribe en el esfuerzo de reconstrucción del país al finalizar la Segunda Guerra Mundial, puesto que Francia está destrozada, la población está empobrecida y la demografía es deficiente. Los seguros de enfermedad, discapacidad, familia y vejez aspiran a proteger a los trabajadores y a garantizar su seguridad en el futuro. La idea nace en el seno del Consejo nacional de la resistencia, inspirada por Pierre Laroque, jurista y consejero de Estado, que será entre 1945 y 1951 el primer director de la Seguridad Social. Es cuestión, según sus propias palabras, de construir "un nuevo orden social", de modo que la Seguridad Social sea la prolongación social de la democracia política, una forma de integración de la clase obrera.

La organización de la Seguridad Social se fundamenta en el rechazo de un sistema asistencial en provecho de una lógica de seguro social. En su origen, se trata de un compromiso entre las pretensiones universalistas y unitarias de Beveridge y la lógica aseguradora de Bismarck (Merrien, 1997). El objetivo del régimen único será rápidamente abandonado, excepto para el seguro familiar cuya unidad era efectiva antes de la guerra. Perdurarán finalmente los regímenes especiales de los trabajadores del Banco de Francia, de los funcionarios, de los agentes del ferrocarril, de los mineros o de los agentes de EDF (Electricidad de Francia), que disponían desde hace mucho

2 AGIRC (Asociación General de las Instituciones de Jubilación de Cuadros) gestiona el régimen de jubilación de los cuadros del sector privado de la industria, el comercio, los servicios y la agricultura. Tiene como misiones: 1) informar, coordinar y controlar las instituciones AGIRC; 2) centralizar los resultados estadísticos y financieros; y 3 ) realizar previsiones. 
tiempo de una protección social organizada. En nombre de los "derechos conquistados", sus beneficiarios se oponen a la integración en el régimen general, lo que habría significado unas prestaciones inferiores. Con unas prestaciones contributivas proporcionales a los salarios, financiadas únicamente por las cotizaciones salariales y no por el impuesto al que se somete la totalidad de los ingresos, el sistema se parece cada vez más al modelo bismarckiano.

La gestión de la Seguridad Social es confiada a las organizaciones sindicales y patronales. En 1945, los sindicatos consiguen por designación las tres cuartas partes de los puestos de administradores. Como observa Catrice-Lorey (1997: 88), "tanto los empresarios como los mutualistas son los grandes perdedores de esta operación”, ya que la composición de los consejos refleja una relación de fuerzas favorable a los sindicatos y a su concepción de la democracia obrera. La mutualidad, responsable desde 1930 de las empresas de seguro obligatorio, percibida como una fuerza conservadora, deja de ocupar un lugar determinante en los consejos de administración de la Seguridad Social. Su papel se limita a partir de entonces a unas acciones de prevención, de solidaridad y de ayuda mutua. Para sus afiliados funciona igualmente como una sección local de las organizaciones de seguro de enfermedad.

No obstante, las modalidades de designación de los administradores cambian constantemente. Así, la CFTC (Confederación Francesa de Trabajadores Cristianos) cuestiona la modalidad del reparto y no desea participar en los consejos de administración, al habérsele concedido un solo puesto en contraste con los siete asignados a la CGT (Confederación General de Trabajadores). En 1946, se modifica este sistema para introducir la elección de los administradores, pero sin cuestionar la regla de las cuotas. Las elecciones de 1947 constituyen una relativa sorpresa, puesto que la CFTC consigue el $26,4 \%$ de los votos y, aunque en declive, la CGT, con más del $40 \%$ de los sufragios, sigue siendo la principal organización sindical. Este dato incide directamente en la disposición Jeanneney de 1967, que introduce un modelo paritario estricto por designación. La representación igualitaria de los agentes sociales modifica el equilibrio político en el seno de los consejos y cristaliza el reparto de los escaños entre las organizaciones. Para la CGT, representa el abandono de la democracia social; filosofía que prefiere a la de la gestión paritaria, de la que tanto FO (Fuerza Obrera) como la CFTC son partidarios. El fundamento electoral y la representación mayoritaria de los trabajadores son instaurados en 1982. El resultado principal de las elecciones organizadas en 1983 es, sin embargo, una tasa de abstención del 50\%, de modo que ninguna organización criticará verdaderamente la decisión tomada en 1996 de volver a las reglas de 1967.

Desde entonces, los consejos de administración locales constan de 8 representantes de las organizaciones sindicales, 8 de la patronal, 2 de las mutuas o de las asociaciones familiares y 4 personalidades cualificadas. Por su parte, los consejos nacionales constan de 13 representantes de las centrales sindicales, 13 de la patronal, 3 de la mutualidad francesa para la Caja Nacional del Seguro de Enfermedad de los 64 Trabajadores Asalariados y 5 representantes de la Unión Nacional de las Asociaciones 
Familiares para la Caja Nacional de Ayudas Familiares, así como de 4 personalidades cualificadas.

Estas modalidades son parcialmente simbólicas, puesto que ninguna de las partes puede imponer a la otra unas decisiones importantes. Sería contrario al espíritu de una regulación negociada, incluso desde el punto de vista de la democracia social en la que los administradores asalariados son mayoritarios. Sin embargo, tienen su importancia para la elección de los presidentes de las Cajas, teniendo en cuenta la división sindical. Efectivamente, con independencia de que las organizaciones sindicales sean mayoritarias o no, los votos en el seno de los consejos de administración pueden conducir a unos resultados que no reflejan la relación de fuerzas intersindicales provenientes de las urnas. Si bien la CGT ha sido siempre el sindicato que ha conseguido el mayor número de votos, jamás ha dirigido una caja nacional y tan solo ha dirigido un escaso número de cajas locales. De hecho, los representantes patronales juegan un papel de árbitro y alimentan las divisiones sindicales. Como observa Friot (1997), a partir de los años 1950, la patronal ha fomentado las divisiones sindicales y "el apoyo de la patronal a los candidatos de FO y posteriormente de la CFDT permitirá excluir ampliamente a la CGT de las presidencias de las cajas". Los efectos de la unidad de acción entre la CGT y la CFDT, concluida en 1966 serán anulados por las disposiciones posteriores.

La autonomía de gestión de los agentes sociales se ejerce en un marco estrictamente definido por el Código de la Seguridad Social. El Estado ejerce una tutela y unas competencias, especialmente financieras, que han ido incrementándose con el tiempo. En nombre de la salvaguarda del interés general y de los derechos estatales, los organismos de la Seguridad Social están sometidos a un control administrativo estricto. La tutela practicada por el ministerio encargado de la Seguridad Social y, especialmente por las Direcciones Nacionales y Regionales de la Seguridad Social, se ejerce sobre las personas y sus actos. Los directores de los organismos nacionales son nombrados por decreto y los demás deben conseguir el consentimiento ministerial. En este sentido, las deliberaciones de los consejos de administración solo llegan a ejecutarse si el Ministerio encargado de la Seguridad Social o el de Economía y Hacienda se oponen a ello. Esta arquitectura institucional de la Seguridad Social constituye la base del modelo social francés. Los derechos sociales son la contrapartida de las cotizaciones sociales salariales, los agentes sociales están asociados a la gestión de las instituciones sociales y el Estado juega un papel clave en la regulación del sistema.

\subsection{Los regímenes complementarios de jubilación}

La existencia de unos regímenes complementarios de jubilación es reconocida en 1945 por una disposición del Código de la Seguridad Social que precisa que estas instituciones solo pueden conceder "una ventajas que se añaden a aquellas que resultan de la organización de la Seguridad Social”. La ley de 22 de mayo de 1946 afirma el principio de la generalización del seguro de enfermedad al conjunto de la pobla- 
ción. No obstante, los afiliados de los regímenes especiales que habían sido instaurados en el sector público, incluso antes de la ley de 1930, y los trabajadores de las empresas privadas que se habían beneficiado de los regímenes complementarios en un marco convencional, temen que sus logros sean cuestionados. Por su parte, los directivos viven su afiliación al nuevo régimen general de la Seguridad Social como una proletarización y manifiestan su descontento.

La patronal se aprovecha de estos temores para desarrollar una visión de la gestión paritaria alternativa a la democracia social de la Seguridad Social. Las negociaciones concluyen el 14 de marzo de 1947 con la creación de la AGIRC (Asociación General de las Instituciones de Jubilación de los Directivos). Este régimen corresponde en cierta medida al proyecto paritario original, ya que los agentes sociales gozan de una representación paritaria y el nivel de cotización así como el acceso a las prestaciones, son fijados por los firmantes del convenio. El Código de la Seguridad Social prevé la obligación de afiliación, la negociación en el marco de los convenios colectivos nacionales interprofesionales y la gestión paritaria por los afiliados y los participantes, trabajadores y antiguos asalariados.

Estos regímenes de jubilación complementarios se extienden progresivamente. En 1957, se crea una unión encargada de favorecer la puesta en marcha de los regímenes complementarios de jubilación para los obreros. En 1961, siempre por convenio, el conjunto de los regímenes complementarios, excepto el de los directivos (ARRCO)3, es federado en una asociación de los regímenes complementarios de jubilación. Por último, la ley del 29 de diciembre de 1972 obliga a todos los trabajadores a afiliarse a un régimen complementario de jubilación. Si la AGIRC es un régimen único desde 1947, el ARRCO solo lo es desde 1994. Sus prestaciones representan alrededor del 40\% de los ingresos de sustitución de los jubilados, aunque existan notables desigualdades según el género, puesto que los hombres tienen unos complementos dos veces superiores a los de las mujeres.

\subsection{El seguro de desempleo}

En 1951, la ratificación por Francia del Convenio Internacional del Desempleo plantea el problema de la protección de los desempleados, que no había sido tomado en consideración tras la Liberación. El Estado se encarga entonces de la indemnización de los parados, aunque las ayudas sean escasas, ya que obedecen más a un principio de asistencia que a una lógica aseguradora. La idea de un seguro de desempleo cobra fuerza a partir de 1956. La CGT-FO inicia el proyecto y será, con el CNPF (Consejo Nacional de la Patronal Francesa) ${ }^{4}$, el copiloto del proceso de negociación. La CGT

3 El ARRCO es una asociación para el régimen complementario de los asalariados que reúne tanto a los trabajadores como a los directivos.

4 El CNPF se crea en diciembre de 1945 a petición del GPRF, o gobierno provisional, que desea 66 tener como interlocutor una organización representativa de la patronal francesa. 
considera por su parte que el seguro por desempleo debería integrar la Seguridad Social y se mantiene al margen de las negociaciones que tienen lugar en 1958. De Gaulle, que acaba de volver al poder, expresa, en una intervención televisada, su deseo de que el proyecto llegue a buen puerto. El 31 de diciembre de 1958, el CNPF, la CGT-FO, la CFTC y la CGC firman un convenio colectivo nacional, reconocido por el Estado, que organiza un régimen de seguro obligatorio contra el riesgo de desempleo. Los trabajadores que han cotizado logran el derecho a una prestación de desempleo. Desde el inicio, la idea de una ayuda de retorno al empleo está presente. La CGT se suma finalmente a los firmantes de 1959, con la creación efectiva de la UNEDIC, que federa las ASSEDIC5.

Inicialmente complementaria con la ayuda pública prestada por el Estado, la coexistencia de dos regímenes se traduce en una reglamentación compleja, fuente de discriminaciones entre los desempleados. El convenio de 1979 fusiona las ayudas públicas y la ayuda del seguro por desempleo en un solo régimen. La crisis financiera, resultante en parte del aumento del paro, conduce al Gobierno (1984) a instaurar una estricta separación de las responsabilidades del Estado y de la UNEDIC. De este modo, existen dos regímenes separados desde entonces. El régimen de seguro por desempleo, financiado por las contribuciones de los empleadores y de los trabajadores, indemniza a los desempleados que han cotizado a lo largo de su trayectoria profesional y se rige por unos convenios firmados cada tres años, desde 1979 por los agentes sociales. Estos convenios fijan el nivel de las contribuciones, así como la cuantía y la duración de las ayudas que dependen de los salarios anteriores. La UNEDIC gestiona el sistema y tanto las treinta ASSEDIC regionales como el GARP ${ }^{6}$ Io ponen en marcha.

El régimen de solidaridad funciona para las personas que no están o que han dejado de estar cubiertas por el régimen de seguro. Es un régimen de asistencia financiado por el presupuesto del Estado que concede unas ayudas de solidaridad de una cuantía fijada y según unas reglas determinadas por los poderes públicos. Este régimen está gestionado por el seguro de desempleo. Durante su primer año de funcionamiento, la UNEDIC indemniza a 24.000 desempleados. La cotización inicial se eleva al $1 \%$ del salario. El escaso nivel de desempleo durante la posguerra permite reducir la tasa al 0,25\% en 1961, pero con el incremento del número de desempleados a partir de 1968 , las cotizaciones no dejan de aumentar. El convenio de la UNEDIC, firmado en 2006 y válido hasta 2008, ha fijado la tasa de cotización en el 6,48\%. En 2006, han sido

5 Las Asociaciones para el Empleo en la Industria y el Comercio conocidas como ASSEDIC se constituyen en 1958 y permanecen hasta la aprobación de la ley del 13 de febrero de 2008 relativa a la reforma de la organización del servicio público del empleo que procede a la fusión, el 1 de enero de 2009, de las ASSEDIC y de la ANPE (Agencia Nacional Para el Empleo) en un nuevo organismo denominado Polo empleo. Las misiones de las ASSEDIC consisten en: 1) afiliar a las empresas, 2) proceder a la inscripción de los desempleados, 3) recaudar las cotizaciones sociales y realizar el pago de las indemnizaciones por desempleo, y 4) asegurar el seguimiento y el acompañamiento de los parados, en colaboración con la ANPE. Entre las 30 ASSEDIC existentes en Francia, cada una está dotada de un Consejo de administración paritario. Las ASSEDIC están coordinadas a nivel nacional por la Unión nacional interprofesional para el empleo en la industria y el comercio (UNEDIC).

6 Agrupación de las ASSEDIC en la región parisina. 
instruidos más de siete millones de expedientes, pero únicamente el 45\% de los parados fueron indemnizados.

\subsection{La formación profesional}

La formación profesional continua forma el cuarto ámbito de actuación de la gestión paritaria. Su desarrollo se produce en 1969, cuando se inician las negociaciones en el contexto de la "Nueva sociedad" de Jacques Chaban-Delmas que se inspira de los trabajos de Michel Crozier (1970), que tiene como ambición refundar las relaciones laborales en Francia. Dirigida pos su asesor, Jacques Delors, la formación profesional tiene vocación de estar en el centro de la negociación entre los agentes sociales antes de dar lugar a una acción legislativa. Delors la presenta a la vez como un instrumento para adaptar la formación de la mano de obra a las nuevas necesidades empresariales y como una posibilidad de promoción social, ofreciendo una segunda oportunidad a los trabajadores. Vincent (1997) señala que el gobierno de ChabanDelmas se ve obligado a utilizar el término "conversación" para llevar a la mesa de negociaciones a una patronal que rechaza categóricamente cualquier idea de iniciar unas verdaderas negociaciones.

Sin embargo, los agentes sociales llegan a un acuerdo en julio de 1970, que mejora los derechos para la formación de los trabajadores despedidos, confirma el derecho para la formación durante la jornada laboral y obliga el empleador a consultar al comité de empresa sobre el plan de formación. La ley de julio de 1971 prolonga y completa el acuerdo, pero "aspira a renovar completamente su espíritu inscribiéndolo en un dispositivo de educación permanente”. La ley obliga a las empresas a una financiación de la formación profesional (el 0,8\% de la masa salarial en 1972, antes de pasar al $1,6 \%$ en 2003), crea el "permiso individual” para la formación, prevé unas instituciones paritarias de recaudación, de mutualización y de gestión de los fondos de formación. Las empresas pueden hacer frente a su obligación de financiación de la formación emprendiendo formaciones o dando su contribución a unos organismos especializados. El dinero así recaudado puede ser utilizado por las empresas que han presentado una solicitud o para realizar otras acciones de formación.

Criticado por su opacidad, su complejidad y las numerosas excepciones aportadas al principio paritario, este sistema ha sido profundamente reformado por la ley quinquenal de 1993 que impone, a través de unos acuerdos sectoriales, la creación de los Organismos Paritarios Recaudadores (OPCA), cuyas competencias son precisadas. En 2006, se contabilizan 99 OPCA, que recaudan más de cuatro billones de euros. Compuestos de manera igualitaria por los representantes sindicales y patronales, estos organismos deben recibir el consentimiento de los poderes públicos. Desde la ley de 2004 , su poder se ha incrementado, ya que deben recibir el $44 \%$ de las contribuciones de las empresas de más de 10 trabajadores y la totalidad de las contribuciones de las empresas de menos de 10 trabajadores. Para Cahuc y Zylberberg (2006:46), muy 68 críticos hacia el sistema de formación profesional para adultos, los OPCA "tienen un 
poder considerable en la orientación del mercado de la formación profesional” ya que constituyen "unas importantes fuentes de distorsión de competencia en favor de los prestadores de formación próximos a los OPCA”.

Por lo tanto, la gestión paritaria concierne únicamente a estos organismos mutualizadores. Efectivamente, a nivel central, desde 1970, las reglas en materia de formación profesional continua están determinadas por unos acuerdos interprofesionales que figuran generalmente en unas leyes y que están completados por unos acuerdos sectoriales. Si este modo de elaboración de las normas ha permitido sin lugar a dudas, ampliar y diversificar los derechos de los trabajadores, no ha conseguido reducir las desigualdades de acceso a la formación entre los menos cualificados y los más formados. El acuerdo de 2003, sobre la formación a lo largo de la vida, figura en la ley del 4 de mayo de 2004, ejemplo emblemático de la abundancia convencional y legal, intenta mejorar el sistema creando un derecho individual a la formación bajo la forma de un crédito anual de 20 horas acumulable durante seis años.

Tampoco existe una gestión paritaria en el seno de la empresa. Como contrapartida de su obligación de financiación, el empleador decide libremente cuáles son las acciones emprendidas en el marco del plan de formación, con la condición de consultar anteriormente el comité de empresa. Sin embargo, los representantes del personal tienen a menudo una influencia limitada sobre el contenido de este plan y el reparto del gasto.

\subsection{Los Consejos de prud'hommes}

Los prud'hommes constituyen la más antigua institución paritaria (Cotterau, 1987). El primer Consejo fue creado el 18 de marzo de 1806, en la región de Lyon, para responder a la solicitud de los fabricantes de la industria de la seda. Los empresarios temían el desorden social creado durante el periodo revolucionario y consideraban que las vías represivas carecían de efectividad. Temiendo la transformación de las empresas en verdaderos “campos de batalla", asignaron "a los prud'hommes la función de reconstruir un orden industrial haciendo reconocer una reglas que sean legítimas para todos" (Fridenson, 2000 : 409). Napoleón decide que la jurisdicción podría extenderse a todos los lugares en los que fuera necesario. Si en 1830 existen 53 consejos de prud'hommes, son 71 en 1848 y 270 en 2007. El decreto de 27 de mayo de 1848 instaura la paridad del Consejo y fija el principio de elección de los consejeros de los prud'hommes por todos los profesionales, incluyendo los trabajadores. La presidencia es ejercida alternativamente por un empresario o un trabajador. Entre 1905 y 1907, unas nuevas leyes sientan las bases del sistema actual, creando las secciones especializadas, abandonando la paridad total, instaurando el recurso al juez en caso de igualdad de voto, extendiendo la competencia de los consejos a los empleadores y a los asalariados del comercio, y reconociendo a las mujeres el derecho de votar y de ser elegidas. El régimen es renovado por la ley Boulin de 18 de enero de 1979 (Michel y Willemez, 2008). 
Las cinco secciones (industria, comercio, actividades variadas, agricultura y dirección) se generalizan. Los gastos de personal y de funcionamiento son asumidos por el Estado y, además, los consejeros, indemnizados y formados, se benefician de una protección contra el despido. Los trabajadores son inscritos en las listas electorales por sus empleadores, las elecciones tienen lugar durante la jornada laboral, el modo de escrutinio es la representación proporcional y los consejeros prud'hommales son elegidos por cinco años, renovándose por mitades cada tres años. El Consejo de prud'hommes es la primera jurisdicción cuando se produce un litigio a propósito de la ejecución y de la ruptura del contrato laboral entre el empleador y el empleado del sector privado, o cuando se trata de trabajadores del sector público que ejercen su actividad laboral en las condiciones regidas por el derecho privado. El Consejo de prud'hommes es igualmente competente para decidir sobre un conflicto que enfrenta a dos trabajadores. El litigio debe concernir preferentemente a un problema individual, si bien la mayoría de los litigios laborales colectivos son competencia de tribunales de instancia superior. En el marco de sus funciones, los consejeros prud'hommales se encargan de la mediación entre las partes cuyo procedimiento que representa una proporción notable de su actividad (aproximadamente del 20\%). Para algunas situaciones, existe un procedimiento de urgencia que conduce a una decisión rápida (Fridenson, 2000: 412).

Los consejeros prud'hommales se benefician de un estatus especial. Tratándose de consejeros asalariados, los empleadores tienen la obligación de dejarles el tiempo necesario para asistir y participar en las actividades prud'hommales. Su ausencia de la empresa, justificada por el ejercicio de sus funciones, no debe conllevar ninguna disminución de su remuneración ni de sus ventajas. Además, el tiempo pasado fuera de la empresa durante las horas de trabajo por los consejeros del colegio trabajador, en el ejercicio de sus funciones se asimila a un tiempo de trabajo efectivo para la determinación de los derechos que el asalariado posee en función de su contrato de trabajo y de las disposiciones legislativas, reglamentarias y convencionales. Como jurisdicción de excepción, paritaria y electiva, el consejo de prud'hommes constituye una institución original cuya elección es uno de los principales test de representatividad para los sindicatos de trabajadores.

\section{ALCANCE Y LÍMITES DE LA GESTIÓN PARITARIA}

Hablar de crisis del modelo paritario se ha convertido en algo habitual, ya que numerosos observadores consideran que los agentes sociales carecen de autonomía en la gestión paritaria y que el Estado se ha convertido en el actor principal. Se piensa a menudo que todas las grandes reformas de la Seguridad Social y de la UNEDIC han sido impuestas y decididas por el Estado. Sean cual fueren los poderes delegados a los agentes sociales, se hace un Ilamamiento sistemático al Estado en caso de problemas, especialmente porque los sindicatos tienen dificultades para asumir las reformas impopulares. La gestión paritaria solo sería una ficción y, en el mejor de los casos, se trataría de un tripartidismo. La tutela cada vez más estrecha del Estado sobre 70 las instituciones paritarias constituye un argumento que fortalece semejante análisis. 
No obstante, ¿se puede deducir de todo ello que asistimos a la marginación de los agentes sociales en las instituciones? Para valorar el alcance y los límites de su influencia, conviene ir más allá de los poderes de gestión de sus representantes, para caracterizar este tipo de regulación utilizado en las instituciones de protección social.

\subsection{Una tutela estatal cada vez más estrecha}

La tutela estatal figura en los primeros textos que reglamentan la Seguridad Social. Desde el inicio, el poder político ha conservado competencias fundamentales, tales como el poder de fijar las tasas de cotización y las cuantías de las prestaciones o de definir las reglas del juego y el control de la ejecución correcta del mandato confiado. La acción del Estado es más sutil y menos aparente en los organismos paritarios provenientes de la negociación colectiva. Es cierto que el crecimiento y, posteriormente, la crisis del Estado de bienestar han incrementado la importancia de lo que está en juego estratégicamente en estas instituciones y han conllevado una intervención creciente de los poderes públicos en el ámbito de la protección social. Las modalidades de control de la tutela estatal ejercida por la dirección de la Seguridad Social y las direcciones regionales de la acción sanitaria y social han continuado imponiéndose en los consejos de administración. Las cuentas deficitarias tanto de la Seguridad Social como del seguro de desempleo y el rechazo de los agentes sociales de modificar las tasas de las cotizaciones o su incapacidad para tomar ciertas decisiones, explican el hecho de que el Estado haya tomado el relevo y haya sustituido a los administradores.

En realidad, "la autonomía de gestión” que caracteriza al modelo paritario siempre se ha restringido a la Seguridad Social. Ante la ausencia de un poder de decisión sobre las cotizaciones y prestaciones, los poderes de las Cajas son casi inexistentes en la CNAV7 y muy limitados tanto en la CNSE (Caja Nacional de Seguro de Enfermedad) como en la CNAF (Caja Nacional de Ayudas Familiares) en las cuales el Estado tiene la costumbre de modificar numerosas prestaciones familiares sin concertación alguna (Adam, 2000: 156). A pesar de la delegación de competencias de la que se benefician las Cajas para gestionar las relaciones con los profesionales sanitarios, la responsabilidad política corresponde al ministro. Cuando se produce un incidente en este sector, los profesionales de la sanidad se dirigen al Estado, éste es interpelado por los parlamentarios en caso de dificultad y es considerado por la opinión pública como el principal responsable de los resultados obtenidos en este ámbito.

Como explican Labbé y Nezosi (2007), el nombramiento de los dirigentes ha escapado muy rápidamente al control de los agentes sociales. Hasta 1960, los consejos de administración nombraban a los agentes de dirección, lo que los situaba de hecho

7 La Caja Nacional de Seguro de Vejez, gestiona la rama de jubilación del régimen general de la Seguridad Social: las pensiones básicas de los trabajadores del comercio, la industria y los servicios. En 2007, el régimen general de la Seguridad Social agrupa a 16,8 millones de cotizantes y a 11,9 millones de jubilados, lo que lo convierte en el principal régimen de jubilación de Francia. 
bajo su control. Este poder ha sido cuestionado en 1960 con la instauración de una lista de habilidades definidas por el ministerio. La creación del Centro Nacional de Estudios Superiores de la Seguridad Social (CNESS) y posteriormente el consentimiento ministerial ante cualquier nombramiento de cargos directivos, han limitado su poder. Desde 1967, los directores de las Cajas nacionales son nombrados en Consejo de Ministros y, desde 1996, el director nacional controla el nombramiento de los directores de las Cajas, cuando se trataba anteriormente de la competencia de los consejos de administración paritarios.

La reforma de 1996 ha culminado un largo proceso de control cada vez más estrecho por una ley orgánica que confiere al Parlamento la responsabilidad de votar anualmente la ley de financiación de la Seguridad Social. Ha creado igualmente los Convenios de Objetivo y de Gestión (COG). Los actores de la Seguridad Social acuerdan con el Estado unos objetivos y unos resultados para un periodo de cuatro años. Aunque para Hassenteufel, el seguro de enfermedad sea una regulación paritaria ilusoria, las disposiciones de 1996, "lejos de marginar a los agentes sociales, ofrecen nuevos medios de acción con la condición de que estén capacitados para utilizarlos” (IRES, 1997: 186).

Es difícil considerar si la Seguridad Social constituye una verdadera gestión delegada. La reforma del seguro de enfermedad en 2004, que sustituye los consejos de administración y de vigilancia de la CNAMTS (Caja Nacional de Seguro de Enfermedad de los Trabajadores Asalariados) por un simple consejo que fija unas orientaciones, confirma este punto de vista. Algunos consideran que esta reforma pone fin al modelo paritario sin decirlo, con el consentimiento de los agentes sociales. Es por esta falta de autonomía de gestión por lo que el MEDEF (Movimiento de las Empresas de Francia), quiere quedar excluido de la Seguridad Social. Su retirada entre 2001 y 2005 ha demostrado que las instituciones de la Seguridad Social podían funcionar perfectamente sin los administradores patronales. No obstante, para valorar correctamente el alcance de la gestión paritaria, es preciso distinguir el poder cada vez más formal de unos administradores y la influencia que conservan las organizaciones en la toma de decisiones. Incluso en la UNEDIC, la responsabilidad ha pasado desde 1984 de los administradores a las centrales sindicales (Bergeron, 2004: 8).

\subsection{Una regulación compartida}

Centrándose en las cuestiones puramente organizacionales o reglamentarias, el modelo paritario es una ficción, pero si se toma en consideración el peso de las organizaciones en la regulación global y sectorial del sistema de protección social, su papel sigue siendo notable.

Las instituciones paritarias forman una esfera de regulación compartida de lo social situada entre el mercado y el Estado. A la liberación, señalan la voluntad del poder político de asociar los agentes sociales a la definición de la política social y a la gestión de los organismos que constituyen el Estado de bienestar en pleno proceso

72 de construcción. La organización administrativa de la Seguridad Social manifiesta 
esta voluntad de confiar a los interesados, y más especialmente a los representantes de los trabajadores, la tarea de gestionar unas misiones de servicio público asumiendo los derechos sociales de los mismos. No obstante, las relaciones entre el Estado y los agentes sociales en el ámbito paritario son complejas, ya que nunca se ha tratado de autonomía ni de independencia. El Estado jamás ha abdicado de su soberanía en la política social, ya que es un principio que se halla en el corazón del modelo social francés. El hecho de haber elegido el trabajo como piedra angular de la arquitectura del sistema le obliga, sin embargo, a componer con los agentes sociales para su administración y su evolución. Este rol no se ejerce principalmente en los consejos de administración de las instituciones paritarias sino en su regulación global y sectorial, en la cual la influencia de las organizaciones sindicales y patronales es incuestionable.

Como subraya Bruno Palier (Palier, 2006: 10-11), "el contexto institucional específico del sistema francés de protección social determina la forma tomada por estas reformas sectoriales. Todas comparten efectivamente un cierto número de rasgos característicos y deben preservar el sistema en lugar de desmantelarlo. Son negociadas entre el Estado y los agentes sociales, sobre la base de un debate entre el seguro y la solidaridad, y consisten en estrechar los lazos entre las cotizaciones y las prestaciones". Si durante un largo periodo los gobiernos han preferido "aumentar las cotizaciones sociales en lugar de reducir el nivel de las prestaciones sociales para resolver los problemas financieros de la Seguridad Social”, es porque parecía ser la decisión más aceptable para los agentes sociales.

Desde los años 1970, todas las reformas han supuesto unos compromisos más o menos tácitos con los agentes sociales o por lo menos con una parte de estos actores. Es el caso, en 1984, en la UNEDIC y se confirma en las reformas siguientes del seguro de desempleo. Sucede lo mismo tanto con las reformas de las pensiones, desde 1993, como con el seguro de enfermedad. "A partir del momento en que los seguros sociales son gestionados por los agentes sociales, ninguna reforma puede ser impuesta por el Gobierno" (Palier, 2006: 11). La reforma de las pensiones de 2003 solo ha podido hacerse gracias al acuerdo de la CFDT (Confederación Francesa Democrática del Trabajo), de la CFTC y de la CGC. Por lo tanto, si el Estado controla la fijación de la tasa de cotización y el nivel de las prestaciones, solo se puede comprender la lógica de sus decisiones haciendo abstracción de los agentes sociales. Si bien se puede concluir la existencia de un tripartidismo en la Seguridad social, este punto de vista parece ser excesivo para los organismos paritarios provenientes de la negociación colectiva en el seno de los cuales los agentes sociales han podido mantener una autonomía relativa pero real.

\subsection{Un seguro paritario}

Si la gestión paritaria se practica ampliamente en la Seguridad Social, la noción es probablemente más apropiada en la UNEDIC y en los regímenes complementarios de jubilación. A pesar de los puntos de vista a menudo divergentes de la patronal y de los sindicatos, los agentes sociales saben realizar unas concesiones para que estas instituciones puedan resistir a las tensiones que afectan a la protección social. Estas 
concesiones se corresponden, para cada parte implicada, a unas opciones estratégicas, a veces antiguas.

Según Pollet y Renard (IRES, 1997: 70) la elección del modelo paritario por la patronal representaría, en 1910 y posteriormente en 1930, una línea de defensa para las Cajas de jubilación de origen patronal. "Es el instrumento de un doble rechazo: el del control de las instituciones de protección social por el Estado y el de su administración por los beneficiarios". Se trata de la misma estrategia que fue utilizada en 1947, durante la creación de los regímenes complementarios de jubilación. Si bien la patronal parece estar dispuesta a no asistir a los consejos de administración de la Seguridad Social, desea sin embargo mantener las instituciones paritarias fruto de la negociación colectiva. Sus objetivos se enfrentan a los intereses de las organizaciones sindicales, para las cuales los organismos paritarios representan unos recursos políticos y materiales de suma importancia.

En las instituciones paritarias, la autonomía de gestión es mucho más real, incluso cuando las tasas de cotización están impuestas o negociadas en unos protocolos tripartitos. Si bien las negociaciones sobre las pensiones del régimen general generan fuertes oposiciones entre los agentes sociales, en el seno de las Cajas complementarias de jubilación (AGIRC y ARRCO), los agentes sociales han demostrado su compromiso a la hora de tomar unas medidas necesarias para mantener el equilibrio financiero de estos regímenes. Pero ello no significa la ausencia o la falta de interés del Estado, que se halla siempre entre bastidores. Ante una cierta deriva de los regímenes complementarios de jubilación, que conducen a unas colaboraciones con las compañías privadas de seguro con las cuales estos regímenes compiten, la ley de 8 de agosto de 1994 obliga a una separación contable y jurídica entre las operaciones de jubilación y las de prevención (Adam, 2000: 163).

En realidad, se enfrentan más a una desviación que al cuestionamiento de los organismos paritarios. Esta desviación se hace en parte con el consentimiento de los agentes sociales que aceptan una distinción creciente entre el seguro y la solidaridad. En este sentido, la reforma de la UNEDIC de 1984 es un modelo, en la medida en que, ante el incremento del desempleo de masas y el notable déficit del régimen, el CNPF, que deseaba ver al Estado asumir una amplia parte de la financiación de las indemnizaciones por desempleo y que rechaza cualquier aumento de las cotizaciones sociales, denuncia en 1982 el convenio UNEDIC, obligando el Gobierno a gestionar el régimen por decreto durante dos años. El Estado modifica la cuantía de las ayudas y la tasa de las contribuciones. Y la nueva reglamentación distingue dos regímenes, uno que obedece a la lógica del seguro y de la gestión paritaria y otro a la lógica de la solidaridad y del Estado. Los seguros sociales gestionados paritariamente aumentan la contribución de las prestaciones, así como el vínculo entre las cotizaciones y las prestaciones. Las prestaciones públicas son menos desiguales y provienen de la solidaridad nacional y del impuesto.

En consecuencia, al lado del sistema de seguros sociales han aparecido unas nue74 vas medidas que rompen con la lógica del sistema. La creación de la CSG (Contribu- 
ción Social Generalizada) ${ }^{8}$ representa una de las decisiones más relevantes, ya que, sustituyendo una parte de las cotizaciones asentadas sobre el salario por un impuesto que concierne al conjunto de las rentas y que está destinada a la protección social, afecta al principio central de la financiación basada en el trabajo. Todo ello cuestiona el papel privilegiado de los interesados en la gestión del sistema y una concepción muy sectorial del Estado de bienestar. De hecho, la reforma ha sido muy criticada por la CGT. El voto anual de una ley de financiación de la Seguridad Social ha venido a completar esta evolución.

\section{CONCLUSIÓN}

La cuestión de la "verdadera" o de la "falsa" gestión paritaria hace referencia a las especificidades del modelo social francés. En este modelo, el rol desempeñado por el Estado es central, se presume la representatividad de los agentes sociales y es relativa la autonomía de la negociación colectiva. Nunca ha existido una autonomía contractual en la protección social, ni de una gestión compartida de las instituciones, como en Alemania, donde el Estado no tiene el monopolio de la fijación de las cotizaciones y de las prestaciones. Para Denis Kessler, uno de los responsables del MEDEF, el modelo paritario consagra una división entre lo económico y lo social: "Todo sucede como si un Yalta implícito había decidido que el progreso social pasaba por una redistribución de los recursos decidida entre los agentes sociales y por una gestión colectiva de los diversos riesgos de la vida".

Este modelo paritario redistribuidor de las rentas y gestor del riesgo no se ha beneficiado de ningún poder en materia económica y especialmente en el seno de las empresas. En Francia, el pacto social ha consagrado, en definitiva, la noción de no-inclusión de los sindicatos en el ámbito económico y una formidable integración de estos en la vida social” (Kessler, Gourcuechon, y Simompoli, 1994:178). Como explican Duclos y Mériaux (Duclos y Meriaux ,2001: 19-33) “el objetivo perseguido es aprovechar la capacidad de las organizaciones sindicales y patronales para conseguir unos apoyos, con el fin de incrementar la legitimidad y la efectividad de la acción pública". El fenómeno se fundamenta en un "intercambio político implícito que procura al fuerte el beneficio de las capacidades del débil para conseguir unos apoyos y producir consentimiento. Se trata de aumentar su dotación para restaurar sus capacidades de control a cambio precisamente de su participación en el control social” (Duclos, 2006: 94).

Es cierto que más allá del reto de las políticas de protección social, la gestión paritaria consagra la representatividad de los agentes sociales. "El Estado organiza y garantiza principalmente la situación de oligopolio representativo, con todas las ventajas asociadas en términos de información y de presencia en los círculos de decisión. Abre así a los agentes sociales el acceso a unos recursos que les permiten, entre otros aspectos, disminuir la presión de la afiliación: las subvenciones públicas, la gestión de

8 La CSG es un impuesto instaurado el 16 de noviembre de 1990, cuya recaudación permite financiar la Seguridad Social. 
un mercado laboral interior y la flexibilidad del control estatal sobre los órganos paritarios" (Duclos, 2006: 94). El intercambio político se enfrenta sin embargo a dos dificultades. En la gestión de las instituciones paritarias, el socio sindical tiene problemas crecientes para hacer valer su representatividad y para afirmar un poder de control social, a pesar de tener una capacidad movilizadora. Esta situación puede estar vinculada al hecho de que su poder institucional está percibido cada vez más como la réplica de las desigualdades del asalariado.

Con los regímenes especiales, el desarrollo de la lógica aseguradora representa una de las características fundamentales que confirma, a pesar de ciertas especificidades, que Francia pertenece a un tipo de Estado de bienestar corporativo. Las desigualdades de la estratificación salarial francesa están inscritas y fortalecidas en y por su sistema de protección social. Unos impuestos elevados, y parcialmente progresivos, bajo la forma de cotizaciones, financian una cobertura selectiva y jerárquica de prestaciones. Lo que se denomina fracaso de la puesta en marcha de un régimen único de Seguridad Social es, en realidad, la elección realizada por una coalición de actores entre los cuales ninguno tenía la capacidad de realizar en su propio ámbito las concesiones necesarias para construir un sistema solidario.

La principal carencia del sistema social galo no es financiera sino democrática. La desigualdad de los derechos sociales, la exclusión duradera del principal sindicato de las presidencias en las Cajas de la Seguridad Social, la exclusión de las categorías marginadas del asalariado en la representación, la presunta representatividad de las organizaciones sindicales debilitan la legitimidad de los dispositivos que presuntamente deben asegurar la democracia social. No obstante, numerosos responsables sindicales no están dispuestos a renunciar a su monopolio de representación en los organismos paritarios, en razón de las ventajas simbólicas y materiales considerables que les están vinculadas.

La cuestión importante que plantea el modelo paritario no es tanto el rol efectivo que desempeñan los agentes sociales en la regulación de la protección social sino las modalidades de regulación que privilegian. La segmentación de los beneficiarios de los derechos sociales, la separación entre el seguro y la solidaridad y el papel creciente de los actores privados, debilitan la credibilidad de las instituciones del Estado de bienestar francés. La cuestión es saber si este sistema es todavía viable para tomar decisiones difíciles. Viable no solamente desde el punto de vista económico, sino también desde la perspectiva de la equidad social para hacer frente a la fragmentación creciente del sistema de protección social galo.

\section{REFERENCIAS BIBLIOGRÁFICAS}

Adam, G. (2000), Les relations sociales, année zéro. Paris: Bayard.

Bergeron, A. (2004), Assurance-chômage: le récit d'André Bergeron. Les Etudes sociales et syndicales, Institute Superior du Travail, Paris. En línea: <http://www.istra76 vail.com/article193.html> (Consulta: marzo 2009) 
Cahuc, P. y Zylberberg, A. (2006), La formation professionnelle des adultes: un système à la dérive. Paris: Centre d'Observatoire Economique de la Cámara de Comercio y de Industria de París (CCIP).

Catrice-Lorey, A. (1997), “ La sécurité sociale en France, institution anti-paritaire? Un regard historique à long terme ", Revue de I'Institute des Recherches Economiques et Sociales, 24: 81-105.

Cottereau, A. (1987), “Les prud'hommes aux XIX-XX siècles”, Le Mouvement social, 141. Crozier, M. (1970), La société bloquée. Paris: Seuil.

Daniel, C., Rehfeldt, U. y Vincent, C. (2000), "La régulation paritaire à la française”, Revue française des affaires sociales, 54 (3-4): 119-133.

Duclos, L. (2006), Paritarismes et institutions. Tesis de Doctorado. IEP de Paris.

Duclos, L. y Meriaux, O. (2001). "Autonomie contractuelle et démocratie sociale : las implicites de la refondation”, La Documentation française, Regards sur l'actualité, 19-33.

Fridenson, P. (2000), “Le conflit social “, en A. Burguiere, y J. Revel, eds., Histoire de la France. París: Seuil.

Friot, B. (1997), “Régime général et retraites complémentaires entre 1945 et 1967: le paritarisme contre la démocratie sociale", Revue de l'Institute des Recherches Economiques et Sociales, 24: 107-130.

IRES (1997), "Le paritarisme. Institutions et acteurs", Revue de l'Institute des Recherches Economiques et Sociales, 24.

Labbé, D. y Nezosi, G. (2007), “Négociation collective, paritarisme et Démocratie sociale", Etudes de la documentation française, 5260: 119-146.

Michel, H. y Willemez, L. (2008), “Les prud'hommes et la représentation du monde du travail. Etat et partenaires sociaux dans la réforme d'une juridiction du travail”, en. L. Duclos, G. Groux y O. Meriaux, eds., La politique et la dynamique des relations professionnelles. París: Librería General de Derecho y Jurisprudencia.

Palier, B., (2006), “Les modèles de l'Etat-providence et le système français. Le système français de protection sociale: architecture et évolutions”, Cahiers Français, 330.

Vincent, C. (1997), “De l'accord de juillet 1970 à la loi de 1971: l'échec d'un paritarisme négocié dans la formation professionnelle continue", Revue de l'Institute des Recherches Economiques et Sociales, número especial: 153-173.

Recibido: 13 de marzo de 2009

Aceptado: 10 de septiembre de 2009 